\section{Dangerous chemicals}

SIR-Wahlström' recognizes the ecological and health problems caused by a great number of existing chemicals and suggests a phasing-out procedure for a 'sunset' list West German activities in this area may be relevant.

In 1982, an Advisory Committee on Existing Chemicals of Environmental Relevance (BUA), consisting of representatives from science, industry and government, was established at the Society of German Chemists (GDCh). Under the German Chemicals Act, existing chemicals must be reported to the competent authority if they exhibit properties indicating they may be hazardous, either alone or in combination with other chemicals ( $\$ 4(6)$ ChemG). The goal of that committee is to seek appropriate solutions for dealing with chemicals relevant to health and to the environment by the adoption of voluntary measures. The committee selects and examines existing chemicals for environmental or health purposes as authorized by the German Chemicals Act, using exclusively scientific criteria.

The estimated number of about 100,000 chemicals in the European Inventory of Existing Commercial Substances (EINECS) prevents selection on the basis of strictly quantitative criteria. Even if the necessary resources were available, reliable data for a quantitative evaluation are lacking in most cases.

On the basis of the limited data available, a pragmatic approach has been developed for selection. To this end, a list of chemicals was compiled from various priority lists: the presence of these chemicals in the environment has been proved, or is highly probable; they are industrially important, or are manufactured in large quantities. Approximately 4,500 chemicals were selected in this way, of which about 1,000 were selected because of their occurrence in the environment and their industrial relevance.

After elimination of chemicals subject to special legal regulations, materials of natural origin, inorganic chemicals and chemicals that are unstable in the environment, 512 substances remained. For these substances, data were collected according to eight selection criteria covering environmental exposure and effects. These data were scored in a scoring procedure for selection purposes. The result was a list of 60 chemicals that may be of environmental relevance and which consequently should be treated with priority ${ }^{2}$.

In continuation of this work, a second list of 75 environmentally relevant chemicals was published ${ }^{3}$. There, the production volume of these chemicals served as an additional criterion. The second list is associated with considerable uncertainty because of the partial incompleteness of the data and because their scientific quality could not be checked individually in all cases. This means that, as with the chemicals on the first list, the second list may also include substances that are not hazardous to the environment, and also that some environmentally hazardous chemicals have been omitted. Consequently, a conclusive evaluation is feasible only if all available data have been collected in separate substance reports and if data that may be lacking have been obtained by appropriate testing.

Meanwhile, about 40 such individual substance reports have been published and about 80 reports are being discussed or about to be published. The importance of these substance reports can be illustrated by an example. In the case of pentachlorophenol (PCP), production in West Germany has been shut down voluntarily as a consequence of the report because PCP is considered as a major source of dioxins in the environment ${ }^{4}$. It is disappointing that companies in other countries have not followed these recommendations, but have even increased their production. As long as non-ecological behaviour leading to more profit governs our decisions, no solution to our environmental problems can be expected.

A third priority list is in the process of being evaluated by an ad hoc working group of the advisory committee. In addition, regular scientific symposia provide a platform for the presentation and discussion of the results to the scientific community and the public. Two such symposia have so far been organized under the auspices of the Society of German Chemists.

In conclusion, the commendable fivestep phasing-out procedure suggested by Wahlström has already been realized on a national basis in the West Germany. The selection criteria and priority lists developed by the Advisory Committee on Existing Chemicals of Environmental Relevance could also serve as an international model.

KURT E. GECKELER

ERNST BAYER

Advisory Committee on Existing

Chemicals of Environmental

Relevance (BUA),

Institute of Organic Chemistry,

University of Tübingen,

D-7400 Tübingen, FRG

1. Wahıström, B. Nature 341, 276 (1989).

2. GDCh-Advisory Committee on Existing Chemicals of Environmental Relevance (BUA) Existing Chemicals of Environmental Relevance, Criteria and List of Chemicals $(\mathrm{VCH}$, mental Relevance, Criteria and

3. GDCh-Advisory Committee on Existing Chemicals of Environmental Relevance (BUA) Existing Chemicals of Environmental Relevance II, Selection Criteria and Second Priority List $(\mathrm{VCH}$, Weinheim and New York, 1989).

4. Beratergremium für umweltrelevante Altstoffe (BUA), Pentachiorphenol, BUA-Stoffbericht $3 \mathrm{(VCH}$, Weinheim, 1986)

\section{Counting partners}

SIR-It is true that the average (lifetime) number of heterosexual partners per person should be the same for men and women (Nature 342, 12; 1989), but this will be apparent only if the total population is known. Concentration of promiscuity in a small minority of women will cause most samples to show a wide difference between the sexes.

To take a hypothetical example: suppose a population of 10,000 men and 10,000 women in which 9,990 of the women and 1,000 of the men have been faithful to their partners, and in which the remaining 10 women have earned their living by making themselves available to each and every one of the remaining 9,000 men; almost all samples will show the average number of partners as one for the women and ten for the men.

It should not be supposed that most informants have lied but that researchers have had difficulty in finding sufficient numbers of highly promiscuous women. All the more reason for expanding the research!

P. J. STEWART

University of Oxford,

Pauling Human Sciences Centre, Oxford OX2 6QS, UK

\section{Embryo research}

SIR-The dilemma facing the British government in implementing the Warnock recommendations ${ }^{1}$ is that, if experimentation with or destruction of artificially fertilized embryos is prohibited after 14 days, anti-abortionists could demand the same protection for naturally fertilized embryos. One solution is to scrap the arbitrary 14-day limit.

The German government has chosen a second solution. It is about to legislate against any embryo research which is not for that embryo's own benefit. In so doing, the German government is acting on the Nuremberg Codex developed after the Nazi war-crimes trials ${ }^{2}$. Should this not give us pause?

Certain German scientists and doctors rationalized, supported and even participated in the Holocaust ${ }^{3.4}$. This fact is now universally abhorred. But how many of us would not have been among them, given normal concerns for personal and family security and also career pressures? If this is so, we must now ask how many of today's scientific lobby for embryo research are free of such concerns and pressures. If not thus free, may not today's lobby be equally mistaken?

\section{Squitchey Lane,}

Oxford OX2 7LB, UK

1. Nature 341, 673 (1989).

2. Dickman, S. Nature 333, 791 (1988)

3. Müller-Hill, B. Murderous Science (Oxford University Press, 1988).

4. Seidelman, W.E. Nature 337, 300; 341, 180 (1989). 